\title{
Regulated production of activin A and inhibin B throughout the cycle of the seminiferous epithelium in the rat
}

\author{
Y Okuma $^{1}$, A E O'Connor ${ }^{1}$, T Hayashi ${ }^{1}$, K L Loveland ${ }^{1,2}$, D M de Kretser ${ }^{1,2}$ and M P Hedger ${ }^{1}$ \\ ${ }^{1}$ Monash Institute of Medical Research, Monash University, 27-31 Wright Street, Clayton, Victoria 3168, Australia \\ ${ }^{2}$ Australian Research Council Centre of Excellence in Biotechnology and Development, Monash Medical Centre, Melbourne, Victoria, Australia \\ (Requests for offprints should be addressed to M P Hedger; Email: mark.hedger@med.monash.edu.au) \\ (T Hayashi is now at Department of Urology, Saitama Medical University, 1981 Tsujido, Kamoda, Kawagoe, Saitama 350-8550, Japan)
}

\begin{abstract}
Production and regulation of activin A and inhibin B during the cycle of the seminiferous epithelium were investigated in adult rats. Immunohistochemistry localised the activin $\beta_{\mathrm{A}^{-}}$ subunit to the Sertoli cell cytoplasm, with much weaker expression in spermatocytes and spermatids. Both activin A and inhibin $\mathrm{B}$, measured by ELISA were secreted by, seminiferous tubule fragments over $72 \mathrm{~h}$ in culture. Activin A was secreted in a cyclic manner with peak secretion from tubules isolated at stage VIII. Tubules collected during stage VI produced the least activin A. Inhibin B secretion was highest from stage IX-I tubules and lowest from stage VII tubules. Addition of interleukin-1 $\beta$ (IL-1 $\beta$ ) had relatively little effect on activin A or inhibin B secretion in culture. In contrast, the peak secretion of activin A by stage VIII tubules
\end{abstract}

was blocked by co-incubation with an excess of human recombinant IL-1 receptor antagonist, whereas inhibin B secretion increased slightly. Dibutyryl cAMP stimulated activin A secretion by late stage VII and VIII tubules and stimulated inhibin B across all stages. These data indicate that activin $A$ and inhibin $B$ are cyclically regulated within the seminiferous epithelium, with endogenous IL-1 (presumably IL- $1 \alpha$ produced by the Sertoli cells), responsible for a peak of activin A production subsequent to sperm release at stage VIII. These data provide direct evidence that production of activin A and inhibin B by the Sertoli cell is locally modulated by IL- $1 \alpha$, in addition to FSH/cAMP, under the influence of the developing spermatogenic cells.

Journal of Endocrinology (2006) 190, 331-340

\section{Introduction}

Previously, we have shown that Sertoli cells from immature (20-day-old) and adult rat testes respond to stimulation with interleukin-1 (IL-1) in vitro by secreting activin A, and this response is in turn regulated by follicle-stimulating hormone (FSH) through a cAMP-mediated mechanism (Okuma et al. $2005 a, 2005 b$ ). Stimulation of IL-1 $\alpha$ production in Sertoli cells by the bacterial inflammatory agent, lipopolysaccharide (LPS), causes a corresponding stimulatory effect on Sertoli cell activin A production (Okuma et al. 2005b). This action of LPS is partially blocked by co-incubation with an excess of the IL-1 receptor antagonist (IL-1ra), indicating that activin A production in this inflammation model is driven by endogenous IL-1 $\alpha$ production (Gérard et al. 1991, Jonsson et al. 1999). Since both IL- $1 \alpha$ and activin A have regulatory effects on spermatogonial DNA synthesis, proliferation and survival (Mather et al. 1990, Hakovirta et al. 1993a, Meehan et al. 2000), such interactions might underpin the mechanisms driving cyclic spermatogonial development in the adult testis.

In stage-dissected adult rat seminiferous tubules, both IL$1 \alpha$ mRNA and protein are produced at all stages throughout the cycle of the seminiferous epithelium, with the exception of stage VII (Gérard et al. 1991, Söder et al. 1991, Jonsson et al. 1999). Studies suggest that this production is driven by the developing germ cells and residual bodies (Gérard et al. 1992, Wang et al. 1998, Jonsson et al. 1999). Significantly, spermatogonial DNA synthesis is lowest in isolated stage VII tubule fragments, but can be stimulated by addition of exogenous IL-1 $\alpha$ (Parvinen et al. 1991). Nonetheless, IL-1 $\alpha$ alone cannot account for the pattern of spermatogonial DNA synthesis across the entire seminiferous cycle. IL- $1 \alpha$ however, shows a relatively consistent production level at all stages except stage VII, DNA synthesis shows a more complex pattern, with two distinct peaks of synthesis at stages IV-V and at stages VIII-IX (Clermont \& Harvey 1965, Parvinen et al. 1991). This points to the involvement of other regulators in addition to IL- $1 \alpha$. As far as activin $A$ is concerned, expression

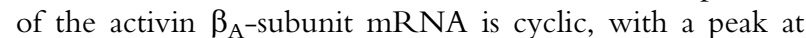
stages IX-XI (Kaipia et al. 1992, Buzzard et al. 2004). Most studies indicate that this is primarily due to the Sertoli cells, although other tubule cells have been implicated as an additional source of the $\beta_{\mathrm{A}}$-subunit, including spermatocytes, spermatids and the peritubular cells (Kaipia et al. 1992, de Winter et al. 1994, Buzzard et al. 2004). 
In a previous study (Okuma et al. 2005a), it was demonstrated that production of inhibin $\mathrm{B}$, which comprises a heterodimer of an $\alpha$-subunit and homologous activin $\beta_{\mathrm{B}^{-}}$ subunit, is regulated in the Sertoli cell by IL-1 in a reciprocal relationship with activin A production. Production of the inhibin B subunits $\left(\alpha\right.$ and $\beta_{\mathrm{B}}$ ) and the inhibin B protein is primarily under the control of circulating FSH, but also displays a cyclical pattern of production, with the highest levels of subunit mRNA at stages XIII-IV and lowest at stages VI-VIII (Bhasin et al. 1989, Kaipia et al. 1991, 1992, Buzzard et al. 2004). Measurement of inhibin protein using a RIA directed against the $\alpha$-subunit of inhibin confirmed that immunoreactive inhibin production mirrors the mRNA expression data with highest levels in tubule fragments from stages XIII-VI and the lowest content and secretion at stages VII-VIII, under both basal and FSH-stimulated conditions (Gonzales et al. 1989, Klaij et al. 1994). This cyclic pattern of inhibin production is consistent with the fact that germ cells have a direct influence on inhibin production mediated via secreted factors (Pineau et al. 1990, Clifton et al. 2002). While $\beta_{\mathrm{B}}$ mRNA and protein expression also have been localised to the germ cells, particularly pachytene spermatocytes and early spermatids in both the human and rat (Andersson et al. 1998, Marchetti et al. 2003, Buzzard et al. 2004), these cells do not appear to significantly express the $\alpha$-subunit and there is some controversy as to whether germ cell expression contributes to the formation of inhibin $\mathrm{B}$ in vivo. There is no assay for the $\beta_{\mathrm{B}}$ homodimer (activin B), hence nothing is known of its production or regulation in the testis at present.

The hypothesis that interaction between endogenous IL$1 \alpha$ and FSH/cAMP plays a role in the cyclic regulation of both activin A and inhibin B in the seminiferous epithelium was investigated using isolated fragments of staged seminiferous tubules from adult rats in culture. Although IL- $1 \alpha$ is the form of IL-1 produced by Sertoli cells, IL-1 $\beta$ is the form that is secreted by monocytes and macrophages during inflammation. Both forms of IL-1 bind to the same receptor with the same range of biological actions, including the stimulation of activin A production by Sertoli cells, and are inhibited by IL-1ra (Okuma et al. 2005a, 2005b). Inflammation in the testis involves production of both IL-1 forms (O'Bryan et al. 2005, Okuma et al. 2005b). Rather than duplicating these studies using both forms of IL- 1 , however, IL- $1 \beta$ was employed as the bioactive ligand for all the studies described herein. In contrast to earlier studies on the expression of activins and inhibins in the seminiferous epithelium, the use of specific two-site ELISAs permitted the measurement of the mature dimeric proteins, rather than just the individual subunits. In addition, the cellular distribution of the $\beta_{\mathrm{A}}$-subunit of activin A was investigated using immunohistochemistry on whole testis sections. Immunohistological localisation of the inhibin $\mathrm{B}$ subunits in the testis of adult rats has been performed by several groups previously (Merchenthaler et al. 1987, Roberts et al. 1989, Shaha et al. 1989, Majdic et al. 1997) and was not repeated in the present study.

\section{Materials and Methods}

\section{Animals}

Adult (80-100-day-old) male Sprague-Dawley rats were obtained from the Central Animal House, Monash University, Victoria, Australia. All studies were approved by the Monash University Animal Ethics Committee and conformed to the Australian Code of Practice for the Care and Use of Animals for Experimental Purposes.

\section{Seminiferous tubule dissection and culture}

Testes were decapsulated immediately post-mortem and individual tubules were isolated using fine forceps under sterile conditions in a Petri dish containing Dulbecco's modified Eagle's medium (DMEM), under an Olympus SZX12 transillumination inverted stereomicroscope (Olympus, Tokyo, Japan). Tubules were staged according to the 14-stage classification (I-XIV) for rat spermatogenesis (Leblond \& Clermont 1952), using the transillumination identification criteria of Parvinen and colleagues (Parvinen \& Ruokonen 1982) and cut into $2 \mathrm{~mm}$ long fragments.

In each culture experiment, ten fragments of each stage or group of stages were used to generate each single replicate. Freshly isolated tubule fragments were homogenised on ice using a glass hand-held homogeniser in $0.5 \mathrm{ml} 0.1 \%$ Triton X-100 (Sigma) in Dulbecco's phosphate-buffered saline for the measurement of cell content. For in vitro production studies, tubule fragments were cultured in $0.5 \mathrm{ml}$ DMEM and $0 \cdot 1 \%$ BSA in 24-well Falcon culture plates (BectonDickinson, Bedford, MA, USA). The medium was supplemented with the appropriate test substances in triplicate wells: $40 \mathrm{U} / \mathrm{ml}$ recombinant human (rh)IL-1 $\beta(200000 \mathrm{U} / \mu \mathrm{g})(\mathrm{R}$ \& D Systems, Minneapolis, MN, USA), $1 \mu \mathrm{g} / \mathrm{ml}$ rhIL-1 IL1ra (Amgen, Thousand Oaks, CA, USA) and $500 \mu \mathrm{g} / \mathrm{ml}$ dibutyryl cAMP (dbcAMP; Sigma). Tubules were cultured at $32^{\circ} \mathrm{C}$ and the media were collected $72 \mathrm{~h}$ later and stored at $-20^{\circ} \mathrm{C}$ prior to analysis. All the experiments were carried out a minimum of twice to confirm the reproducibility of the results.

The use of $72 \mathrm{~h}$ cultures was found to be necessary, as short-term cultures ( 24 and $48 \mathrm{~h}$ ) did not produce sufficient activin $\mathrm{A}$ to be consistently detectable in any except in the peak secretion stages. It has already been established that in $72 \mathrm{~h}$ cultures of seminiferous tubule fragments, there is an on-going progression of the cycle throughout the culture period (Clermont \& Harvey 1965, Parvinen et al. 1991). Dissected tubule fragments collected in stage I, for example, will progress through stages II, III and IV during the culture period, so that the content of the culture medium is a summation of production at all these stages. Similarly, tubule fragments collected during stage VIII progress as far as stage XII during the same period and accumulation of secreted protein in these cultures corresponds to the production during all stages from VIII to XII. 


\section{$\beta_{A^{-} \text {-subunit immunohistochemistry }}$}

Testes were fixed by whole-body vascular perfusion with Bouin's fluid, as previously described (O'Bryan et al. 2000), postfixed for $5 \mathrm{~h}$ and processed for embedding in paraffin by routine procedures. Sections $(5 \mu \mathrm{m}$ thick) were cut and attached to Superfrost Plus Glass slides (BioLabs Scientific, Melbourne, Australia).

In order to detect the $\beta_{\mathrm{A}}$-subunit of activin, sections were de-paraffinised and rehydrated prior to antigen retrieval in $50 \mathrm{mM}$ glycine- $\mathrm{HCl}$ buffer, $\mathrm{pH} 3 \cdot 5$, in a microwave oven $(1350 \mathrm{~W})$ for $2-3 \mathrm{~min}$ at the high-power setting, followed by 7-8 min on the defrost setting. Sections were allowed to cool down to room temperature and washed twice with Trisbuffered saline (TBS: $10 \mathrm{mM}$ Tris, $150 \mathrm{mM} \mathrm{NaCl,} \mathrm{pH} \mathrm{7 \cdot 6),}$ which was used for all subsequent washing steps. Pretreatment with $3 \% \mathrm{H}_{2} \mathrm{O}_{2}$ was performed for $5 \mathrm{~min}$ to inactivate endogenous peroxidases. Sections were incubated in a blocking solution consisting of 5\% normal rabbit serum, $0 \cdot 1 \%$ BSA diluted in TBS for $20 \mathrm{~min}$ and then incubated at $4{ }^{\circ} \mathrm{C}$ with a mouse monoclonal antibody (E4) directed toward the $\beta_{\mathrm{A}}$-subunit of activin (Knight et al. 1996), diluted to $10 \mu \mathrm{g}$ / $\mathrm{ml}$ in blocking solution. Localisation was detected using biotinylated sheep anti-mouse serum (Silenus, Hawthorn, Vic, Australia) diluted to $1 \cdot 28 \mu \mathrm{g} / \mathrm{ml}$ in blocking solution as secondary antibody $(1 \mathrm{~h})$, followed by incubation using the Vectastain ABC kit (Vector Laboratories, Burlingame, CA, USA) for $30 \mathrm{~min}$. Staining was visualised with $3,3^{\prime}-$ diaminobenzidine tetrahydrochloride (Sigma; $2 \cdot 13 \mathrm{mg} / \mathrm{ml}$ in TBS) as chromogen. The sections were counterstained with Harris' haematoxylin (Sigma) and mounted under DPX (BDH Laboratory Supply, Poole, UK). Mouse IgG2b (isotype matched to the E4 antibody) was used in place of the primary antibody for negative controls.

Immunohistochemistry results were assessed using an Olympus BX 50 microscope, attached to a 3CCD MTI video camera (Dage-MTI, Michigan City, IN, USA) coupled to a Pentium computer. Photoshop version 5.5 (Adobe Systems) was used to generate photomicrographs. Cross-sections of seminiferous tubules were staged according to the cell association and morphological criteria using the 14-stage classification for rat spermatogenesis (Leblond \& Clermont 1952).

\section{Activin $A$ and inhibin B ELISA}

Activin A was measured using a specific ELISA (Knight et al. 1996) according to the manufacturer's instructions (Oxford Bio-Innovations, Oxfordshire, UK) with some modifications. This assay measures total activin A and is not affected by the presence of the activin-binding protein, follistatin. The recombinant activin A standard (Robertson et al. 1992) and samples were diluted in culture medium. A 6\% SDS solution in PBS was added ( $3 \%$ final concentration) followed by boiling for $3 \mathrm{~min}$. The samples were allowed to cool before the addition of $\mathrm{H}_{2} \mathrm{O}_{2}$ (2\% final concentration) and subsequent $30 \mathrm{~min}$ incubation. Duplicate samples were added to the E4 (anti- $\beta_{\mathrm{A}}$-subunit) monoclonal antibody-coated plate and incubated overnight at room temperature. The plates were washed and the second detection antibody (biotinylated-E4) was added for $2 \mathrm{~h}$ at room temperature. After washing, alkaline phosphatase linked to streptavidin was added to the wells and incubated at room temperature for $1 \mathrm{~h}$. After further washes, the alkaline phosphatase activity was detected using an amplification kit (ELISA Amplification System; Invitrogen) wherein the substrate was incubated for $1 \mathrm{~h}$ at room temperature. This assay has an intraplate coefficient of variation $(\mathrm{CV})$ of $7 \cdot 4 \%$ and an interplate $\mathrm{CV}$ of $6 \cdot 3 \%$, with a mean assay detection limit of $10 \mathrm{pg} / \mathrm{ml}(n=12$ assays).

Inhibin B was measured using a specific ELISA (Groome et al. 1996) according to the manufacturer's instructions (Oxford Bio-Innovations) with some modifications. The standard used was WHO 96/784 inhibin B reference standard (NIBSC, Potter's Bar, Herts, UK). Standard and samples were diluted in unconditioned culture media containing the same additives as were used in the culture and treated as per the manufacturer's protocol. Duplicates were added to the plates and incubated overnight at room temperature. The plates were washed and the second detection antibody ( $\mathrm{R} 1$ coupled to alkaline phosphatase) was added for $3 \mathrm{~h}$ at room temperature. After washing, the alkaline phosphatase activity was detected using an amplification kit (ELISA Amplification System; Invitrogen) wherein the substrate was incubated for $2 \mathrm{~h}$ at room temperature. This assay has an intraplate $\mathrm{CV}$ of $8 \cdot 6 \%$ and an interplate $\mathrm{CV}$ of $7 \cdot 9 \%$, with a mean assay detection limit of $12 \mathrm{pg} / \mathrm{ml}$ ( $n=7$ assays).

\section{Statistical analyses}

All the data were analysed using one- or two-way ANOVA following appropriate transformations to normalise data and equalise variance, where necessary. Mean values were compared using either Student-Newman-Keuls multiple range test or Dunnett's test for multiple comparisons with a control (Sigmastat version 1.0; Jandel Scientific Software, San Rafael, CA, USA). Differences between responses were considered statistically significant at the $P<0 \cdot 05$ level.

\section{Results}

\section{Expression of activin $A$ during the cycle of the seminiferous epithelium}

In routine preparations using ten fragments/dissected stage, activin A levels in extracts of tubule homogenates were either very close to or below the defined sensitivity of the assay, i.e. $<10 \mathrm{pg} / \mathrm{ml}$ (data not shown). In order to establish the presence of activin A in tubule fragments from all stages of the cycle prior to the start of the cultures, tubule fragments from ten separate experiments were combined to give pooled extracts containing 100 fragments/stage. In these combined extracts, activin A was detectable in homogenates of tubules 
collected at all stages of the cycle (Fig. 1), tending toward the highest levels around stages VIII-XII.

Strong immunostaining for the $\beta_{\mathrm{A}}$-subunit of activin A protein was observed within the cytoplasm of Sertoli cells at all stages of the cycle of the seminiferous epithelium, with much weaker staining associated with the cytoplasm of all meiotic and postmeiotic stages of germ cell development (Fig. 2). The staining within the Sertoli cell cytoplasm appeared distinctly granular and this was particularly noticeable around stages IX-XI (stage XI is shown as an example in Fig. 2d), where at least some of the staining may have been associated with residual bodies. In the interstitial tissue, very strong staining was observed in the cytoplasm of resident immune cells (macrophages and mast cells), with significant albeit weaker staining in most Leydig cell clusters. Neither the peritubular cell nor vascular endothelial cell cytoplasm showed detectable $\beta_{\mathrm{A}}$ labelling in these studies.

\section{Regulation of activin $A$ and inhibin $B$ secretion}

In $72 \mathrm{~h}$ cultures of seminiferous tubules, activin A showed a very distinctive cyclical secretion into the culture medium under basal conditions, with a significantly higher production in tubules collected at stage VIII (Fig. 3a). Activin A levels also appeared to be elevated in some cultures of tubules dissected at stages VII $_{c d}$ (compare Figs 3a and 4e). Production from all other stages was lower, but still detectable. The content of the media collected at the end of the culture for all stages was consistently greater than the levels of activin A present in the tubule fragments at the start of the culture, indicating that activin A was synthesised as well as secreted in the cultures. Addition of IL-1 $\beta$ did not alter the pattern or production substantially (Fig. 3c), however, addition of dbcAMP did extend the duration of the statistically significant peak of secretion to include both stages VII ${ }_{c d}$ and VIII tubule cultures (Fig. 3e). Addition of an excess of IL-1ra completely abrogated the peak of activin A secretion and production across the entire cycle appeared to be reduced relative to cultures under basal conditions, falling below the sensitivity of the assay at stages $\mathrm{I}-\mathrm{V}$ in particular (Fig. $3 \mathrm{~g}$ ).

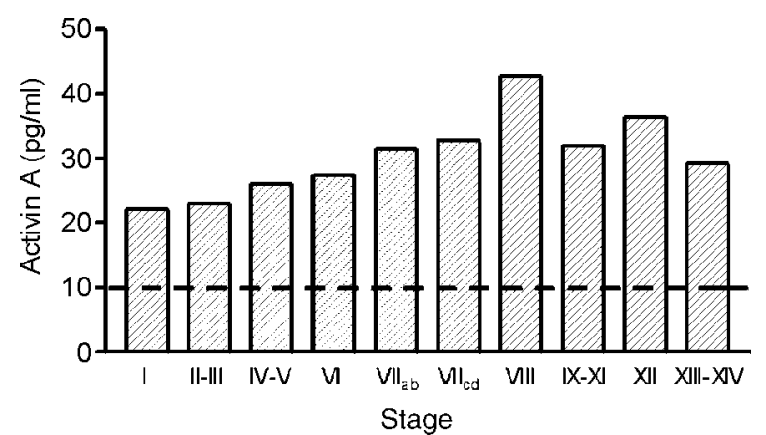

Figure 1 Activin A content measured in homogenates of isolated staged tubules. Values are for homogenates of pooled 100

fragments from each stage in a final extract volume of $0.5 \mathrm{ml}$. The broken line indicates the detection limit of the assay.
Inhibin B also displayed a significant cyclic variation in the secretion in culture, with higher levels in tubules collected at stages XI-I and slightly lower levels between stages IV and VII (Fig. 3b). This cyclic secretion was not evident in cultures with IL-1 $\beta$, although a considerable group variability observed in these cultures would have obscured any subtle difference (Fig. 3d). dbcAMP stimulated inhibin B production at all stages, although the cyclic pattern observed under basal conditions was maintained (Fig. 3f). Addition of IL-1 ra had relatively little apparent effect on the cyclic pattern of inhibin B secretion (Fig. 3h).

The data presented in each panel of Fig. 3 were obtained from three separate experiments comprising the entire range of stages under a single treatment; hence, it was not possible to directly compare the responses to the various treatments relative to one another. In order to establish the secretion of activin A and inhibin B as regulated by IL-1, cAMP and IL$1 \mathrm{ra}$, the effects of these treatments were re-evaluated by direct comparisons in cultures of specific stages around the peak of activin $\mathrm{A}$ secretion. These studies indicated that the addition of IL-1 $\beta$ caused a small, but a significant increase in activin A secretion in cultures of stage VIII (Fig. 4g), but had no effect at the other stages examined (stages VI-VII; Fig. 4a, $c$ and e). It also was confirmed that cAMP caused a significant stimulation of activin A in cultures of late stages VII and VIII (Fig. 4e and g). Addition of IL-1 ra inhibited activin A secretion at stage VIII (Fig. 4g), but no significant effect at the earlier stages studied (VI and VII) was observed (Fig. 4a, c and e). As expected, inhibin B production was stimulated by dbcAMP at all the stages examined, but IL- $1 \beta$ appeared to have no effect (Fig. 4b, d, f and h). Addition of IL-1ra had a small, but significant stimulatory effect on inhibin B secretion at stage VIII (Fig. 4h). These data were entirely consistent with the results obtained in the cultures comparing all the stages of the cycle (Fig. 3).

\section{Discussion}

The data in the present study show that activin A protein is present at all stages of the cycle of the seminiferous epithelium in the adult rat testis. Activin A is particularly associated with the Sertoli cells, but meiotic and postmeiotic germ cells also appear to contain activin $\beta_{\mathrm{A}}$ immunoreactivity. Staining of $\beta_{\mathrm{A}}$ in both Sertoli cells and in spermatogenic cells previously has been identified using rabbit polyclonal antibodies raised against $\beta_{\mathrm{A}}$ synthetic peptides on frozen sections of adult rat testes (Roberts et al. 1989, Shaha et al. 1989), while $\beta_{\mathrm{A}}$ mRNA has been localised to Sertoli cells, spermatocytes and spermatids (Kaipia et al. 1992, Buzzard et al. 2004). Both the expression of mRNA in these earlier studies and the release of activin A by tubule cultures observed in the present study were cyclic. Curiously, activin A was not detectable by immunohistochemistry in the peritubular cells of the adult testis, even though these cells from immature testes secrete activin A in vitro (de Winter et al. 1994, Buzzard et al. 2003, 

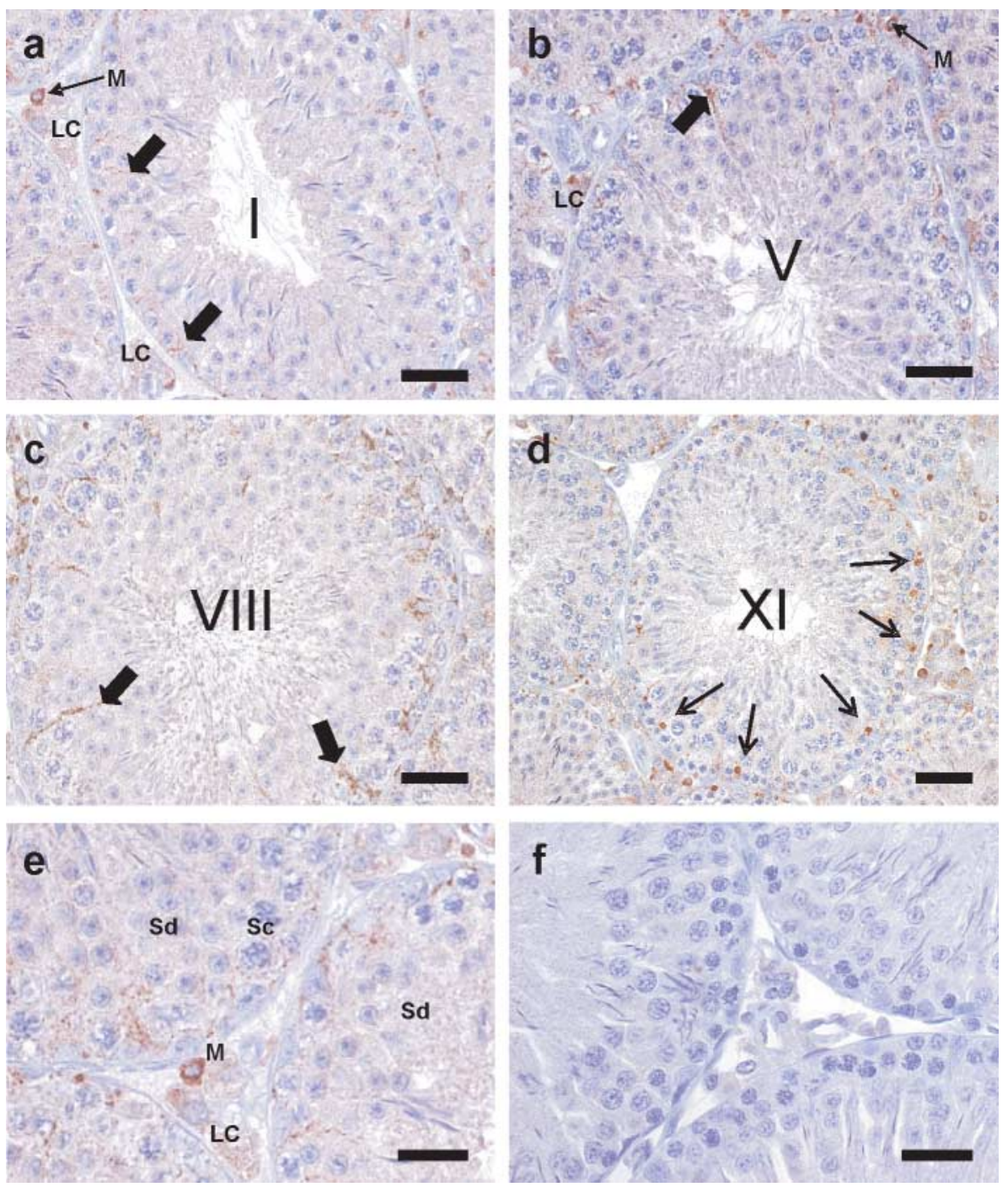

Figure 2 Localisation of the $\beta_{\mathrm{A}}$-subunit of activin $\mathrm{A}$ by immunohistochemistry in adult rat testis. (a) Micrograph showing tubule cross-section at stage I of the cycle of the seminiferous epithelium; (b) stage V; (c) stage VIII; (d) stage XI. Bar inset in (a)-(d)=50 $\mu \mathrm{m}$. (e) High power micrograph showing seminiferous epithelium of several adjacent tubules and interstitial tissue; $(\mathrm{f})$ negative control. Bar in (e) and $(\mathrm{f})=20 \mu \mathrm{m}$. Within all tubule cross-sections, strong immunostaining was observed in the Sertoli cell cytoplasm (large arrows), with significant, but much less intense staining over spermatocyte (Sc) and spermatid (Sd) cytoplasm at all stages of their development (compare (e) with negative control section $(f)$ at same magnification). Note that the Sertoli cell-staining pattern appears as distinct large granules in the basal cytoplasm at stage XI (narrow arrows). In the interstitial tissue, strong staining was associated with macrophages (M), while Leydig cell (LC) clusters showed a consistently weaker staining profile. There was no appreciable immunostaining associated with peritubular cells, basally located spermatogonia or vascular endothelial cells.

Okuma et al. 2005a) and expression of mRNA has been detected in these cells in the adult rat testis by in situ hybridisation (Buzzard et al. 2004). These data suggest that either transcription or storage of activin A by the peritubular cells in the adult testis may be greatly reduced compared to other cell types.

When interpreting the data presented in this study, it is important to recognise that there is an on-going progression of the cycle during the culture period in long-term (72 h) cultures of seminiferous tubule fragments. Consequently, dissected tubule fragments collected at stage VIII can progress as far as stage XII over $72 \mathrm{~h}$ in the culture (Clermont \& Harvey 1965, Parvinen et al. 1991). This means that the peak of activin A production in vitro, which is associated with the stage VIII tubules, overlaps with the peak of $\beta_{A}$ mRNA expression at stages IX-XI, previously reported by 

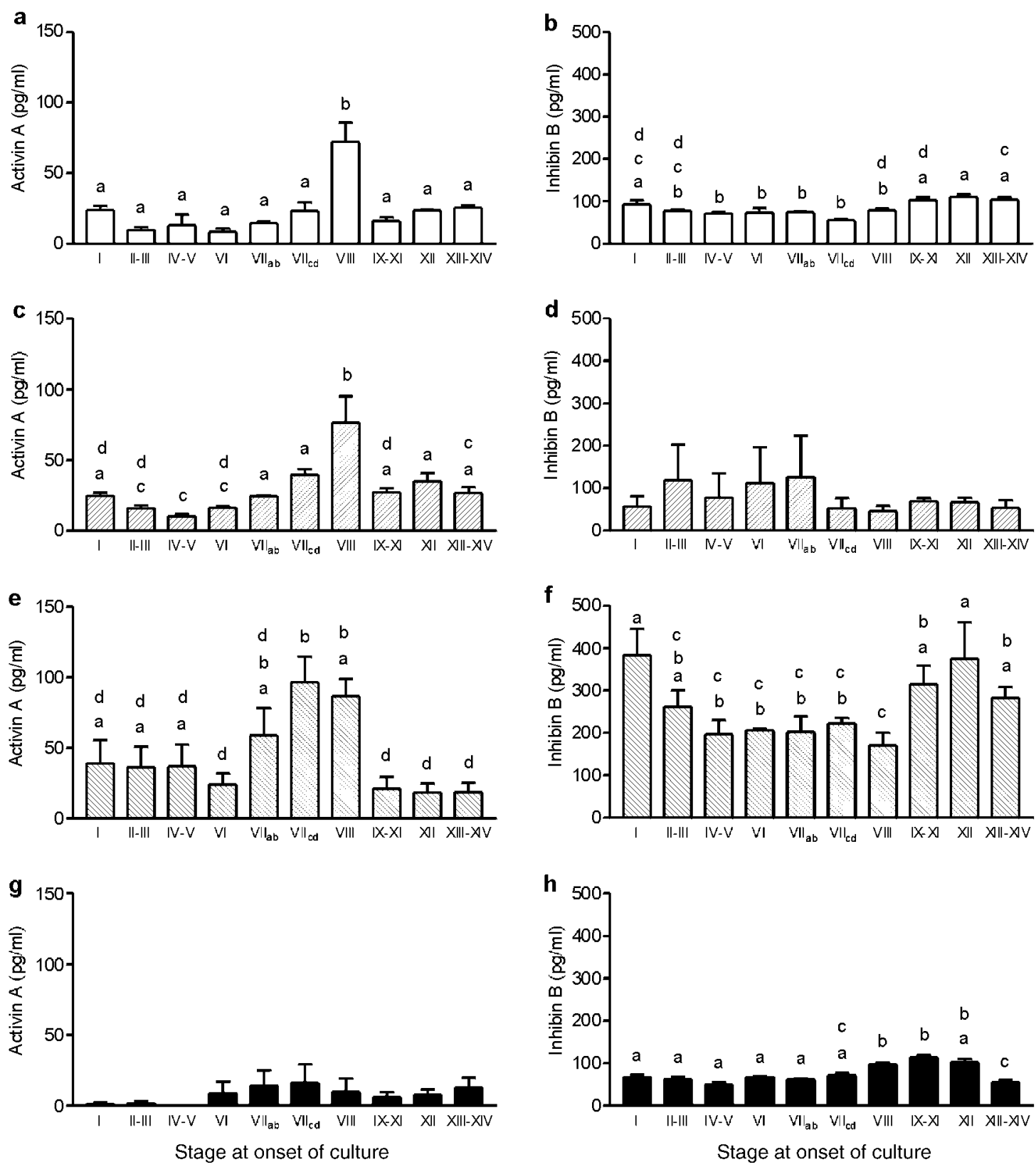

Figure 3 Cyclic secretion of activin A and inhibin B by staged tubules over $72 \mathrm{~h}$ in culture, under basal conditions (a and b), in the presence of interleukin-1 $\beta$ (c and d), dibutyryl cAMP (e and f) and IL-1 receptor antagonist (IL- $1 \mathrm{ra})(\mathrm{g}$ and $\mathrm{h}$ ). Each panel shows the means \pm s.E.M. of three separate cultures and each test substance was assessed in a separate culture. All values with same letter superscript are not significantly different $(P>0 \cdot 05)$. Note that no significant difference in activin A production was detected between the stages in the presence of IL-1 ra (g).

Kaipia and colleagues (1992). Thus, peak activin A synthesis and secretion are found in those stages immediately following the release of sperm into the tubule lumen, which occurs during stage VIII and coincides with the phagocytosis of the residual cytoplasm (summarised in Fig. 5). Studies have shown that, while all germ cells induce IL- $1 \alpha$ production by the Sertoli cells in vitro, the residual bodies are particularly potent stimuli (Gérard et al. 1992, Syed et al. 1995, Wang et al. 1998). In studies on the cyclic expression of IL- $1 \alpha$, production is very low at stage VII and returns to maximum during stage VIII (Söder et al. 1991, Gérard et al. 1992, Syed et al. 1995, Wang et al. 1998, Jonsson et al. 1999). This recovery may be due to the presence of the residual bodies. Peak stimulation of activin A production occurs at this time as well, suggesting 

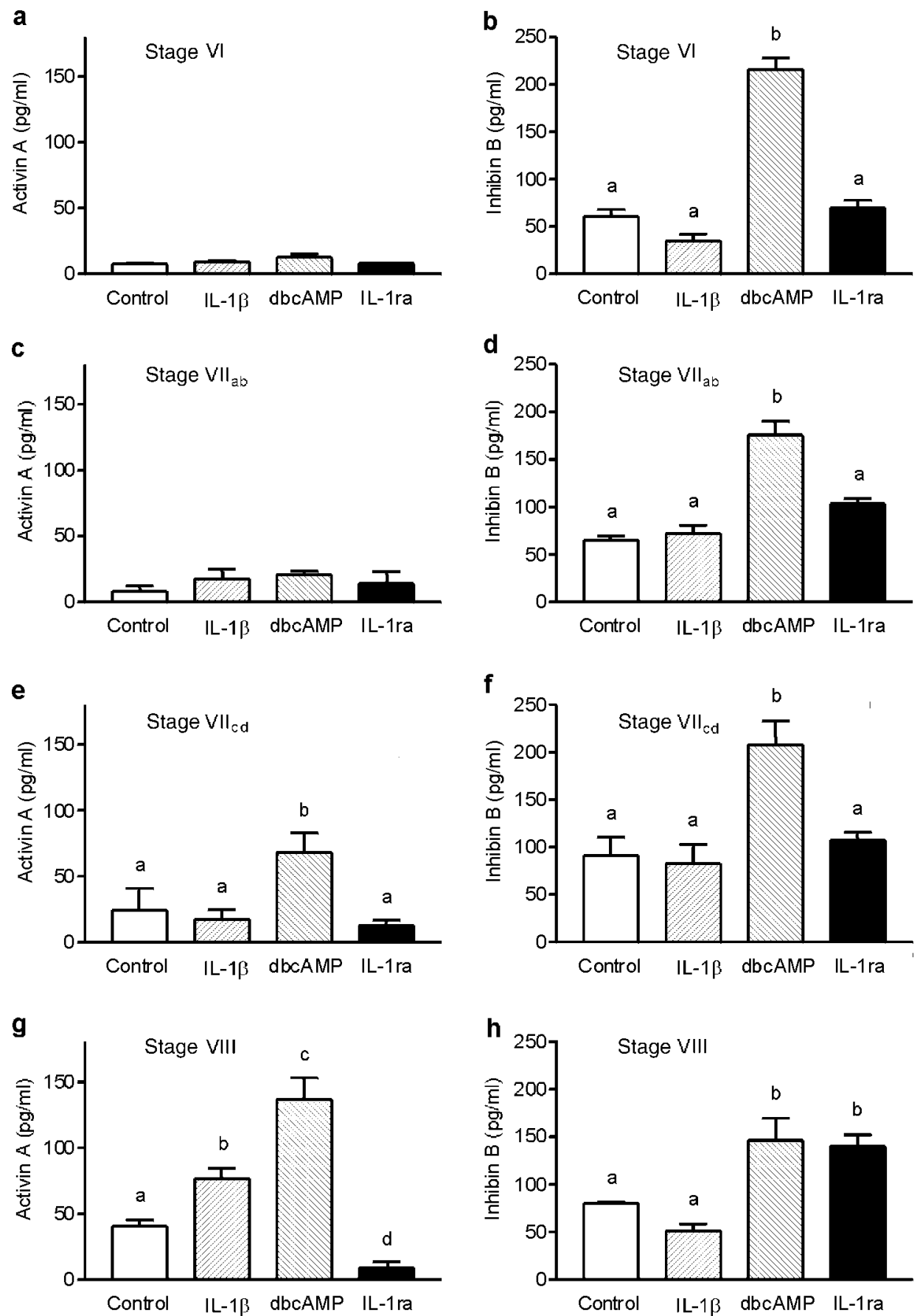

Figure 4 Stage-specific secretion of activin A and inhibin B by tubules at stage $\mathrm{VI}$ (a and b), stage VIlab (c and d), stage VIIcd (e and f) and stage VIII ( $g$ and h), under basal conditions and in the presence of interleukin-1 $\beta$, dibutyrylcAMP and IL-1 receptor antagonist over $72 \mathrm{~h}$ in culture. Data shown are means \pm S.E.M. of triplicate wells from a single representative experiment. All values with same letter superscript are not significantly different $(P>0 \cdot 05)$.

that the surge of activin A production might be driven by the endogenous rise in IL-1 $\alpha$. This was confirmed in the present study using IL-1 ra to block the secretion in vitro. However, since IL- $1 \alpha$ continues to be expressed in the seminiferous epithelium after the peak activin A production has finished, it appears that the Sertoli cell may become less sensitive to stimulation by IL- $1 \alpha$, at least as far as activin A production is concerned, before the end of stage XI. 


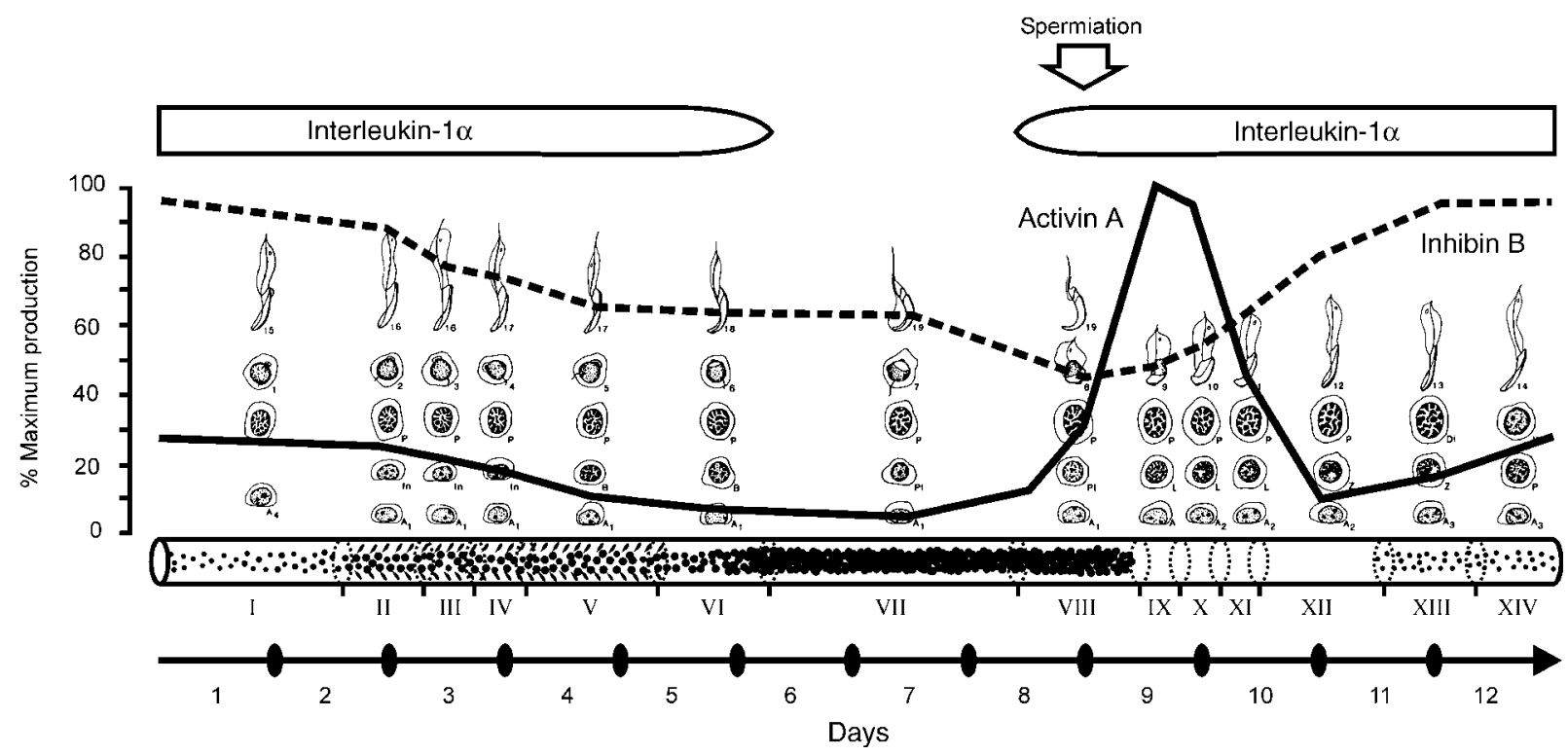

Figure 5 Summary diagram showing the predicted pattern of activin A and inhibin B production, derived by extrapolation of the data in Fig. 3, corresponding with the production of IL- $1 \alpha$ and events of the cycle of the seminiferous epithelium. It is important to recognise that the sampling duration of $72 \mathrm{~h}$ and resulting overlap of sampling time-points means that the placement of some events, such as the exact timing of the commencement of the activin A surge and its subsequent decline, are approximations.

Overall, the data in the present study suggest that IL-1 $\alpha$ may be driving activin A production by the seminiferous tubules at all stages, where IL- $1 \alpha$ is produced, but the ability of the Sertoli cells to respond to IL- $1 \alpha$ is changing throughout the cycle as well. This may involve a change in IL-1 receptor expression or signalling. Alternatively, since IL-1 stimulates IL-1ra secretion by cultured mouse Sertoli cells (Zeyse et al. $2000)$, regulation may involve the induction of endogenous IL-1ra. Regardless of the mechanisms involved, the trigger for synthesis and release of activin A that occurs during stage VIII is followed very quickly by a downregulation of the response, resulting in a transient surge of the production of activin $\mathrm{A}$ around stages IX-XI. This would seem to suggest an important role for activin $\mathrm{A}$ at this time in the cycle, in particular. However, activin A may be retained by the Sertoli cells across several stages of the cycle and may be able to diffuse along the tubule as well, so that activin A produced at one stage of the cycle may be able to influence other stages. Support for this concept of 'action at a distance' comes from the observation that activin A protein levels in the tubule homogenates and tissue sections across the entire cycle of the seminiferous epithelium did not vary as dramatically as the synthesis data would seem to indicate.

Inhibin B also showed a cyclic pattern of production (Fig. 5). The nadir of inhibin production corresponded with the commencement of the activin A surge, consistent with an inhibitory effect of IL- $1 \alpha$ on inhibin B production at this time. In contrast, both cytokines displayed a parallel decline from the levels seen at stage XIV throughout stages I-VI. At present, it is unclear what might be driving the changes in the production of inhibin $\mathrm{B}$ and activin A during this period, although interactions between IL- $1 \alpha, \mathrm{FSH}$ and possibly even testosterone must be presumed to be involved.

The actual functional role of the activin A surge requires elucidation. There is evidence that IL-1 stimulates both mitosis and meiosis by the spermatogonia (Pöllänen et al. 1989, Parvinen et al. 1991, Hakovirta et al. 1993b) and activin A has been shown to regulate spermatogonial proliferation as well, with both stimulatory and inhibitory effects observed in different culture systems (Mather et al. 1990, Hakovirta et al. 1993a, Meehan et al. 2000). Consequently, it is reasonable to hypothesise that the activin $\mathrm{A}$ released in response to upregulation of IL- $1 \alpha$ during stage VIII is involved in modulating the proliferative response of spermatogonia to IL-1 $\alpha$. Moreover, since activin A blocks both IL-1 and IL-6 responses in other cell systems (Phillips et al. 2001), it is possible that activin A modulates the response of spermatogonia to both the cytokines. In turn, activin A is likely to be regulated by its binding protein, follistatin, which is produced by both Sertoli cells and spermatogenic cells within the seminiferous epithelium throughout the cycle, but with peak production at and immediately after the time of the peak production of activin A (Kaipia et al. 1992, Meinhardt et al. 1998).

In contrast to the principal effects of FSH and cAMP on isolated, immature or adult Sertoli cells in culture (Okuma et al. 2005a, 2005b), cAMP was found to stimulate activin A production specifically in cultures of tubule fragments from stages VII and VIII. This observation is consistent with the fact that the $\beta_{\mathrm{A}}$-subunit promoter contains both IL-1-signalling pathway and cAMP-responsive elements 
(Tanimoto et al. 1996, Ardekani et al. 1998, Yoshida et al. 1998). The data also suggest that the reciprocal relationship between the actions of IL-1 and FSH on Sertoli cell, activin A and inhibin B, secretion is modified by the presence of developing spermatogenic cells, consistent with previous observations (Clifton et al. 2002). It should be noted that co-incubation of the stage VIII tubules with IL-1ra caused a reduction in activin $\mathrm{A}$ secretion and a corresponding increase in inhibin $\mathrm{B}$, providing further evidence for the reciprocal regulation of two proteins by IL- $1 \alpha$ at this time. Taken together, the data highlight the considerable complexity of the regulatory interactions involved.

The data suggest that the presence of germ cells also affects the Sertoli cell response to IL-1 $\beta$. In contrast to large upregulation seen in isolated Sertoli cells without significant germ cell contamination (Okuma et al. 2005a, 2005b), exogenous IL-1 $\beta$ significantly affected activin A production by stage VIII tubules only, indicating that germ cells may inhibit the response to inflammatory IL-1 in a stage-specific manner. Alternatively, the fact that IL-1 $\beta$ does not appear to have major effects on activin $A$ in tubules with intact spermatogenesis may be due to the production of endogenous IL- $1 \alpha$ by the tubule fragments.

Finally, although not the focus of this study, it was observed that the Leydig cells and interstitial immune cells (macrophages and mast cells) also contain activin $\beta_{\mathrm{A}}$ immunoreactivity. Whether this is due to the synthesis of activin $A$ by these cell types themselves or uptake of activin A secreted from the Sertoli cells or from the circulation remains to be determined. Previous studies have not reported significant interstitial tissue $\beta_{\mathrm{A}}$ staining in the adult testis (Roberts et al. 1989, Shaha et al. 1989, Majdic et al. 1997), but it should be noted that both macrophages and mast cells produce activin A in other tissues (Erämaa et al. 1992, Cho et al. 2003) and may be important sources in the testis as well.

In conclusion, the data clearly show that, in addition to hormonal control via FSH/cAMP, both activin A and inhibin $\mathrm{B}$ are under continuous regulation throughout the cycle of the seminiferous epithelium and that endogenous IL- $1 \alpha$ is involved. It should be noted, however, that the cycle of the seminiferous epithelium appears to operate in mice lacking the IL-1 receptor and is hence insensitive to either IL- $1 \alpha$ or IL-1 $\beta$ (Cohen \& Pollard 1998). It remains to be discovered whether this means that a link between IL-1 and activin in spermatogenesis is dispensable, or that alternative mechanisms operate in animals that lack the ability to signal through the IL-1 receptor.

\section{Acknowledgements}

This work was supported by grants from the National Health and Medical Research Council of Australia (grant nos. 143786, 143788 and 143792). The authors declare that there is no conflict of interest that would prejudice the impartiality of this scientific work.

\section{References}

Andersson AM, Müller J \& Skakkebaek NE 1998 Different roles of prepubertal and postpubertal germ cells and Sertoli cells in the regulation of serum inhibin B levels. Journal of Clinical Endocrinology and Metabolism $\mathbf{8 3}$ $4451-4458$

Ardekani AM, Romanelli JC \& Mayo KE 1998 Structure of the rat inhibin and activin $\beta_{\mathrm{A}}$-subunit gene and regulation in an ovarian granulosa cell line. Endocrinology 139 3271-3279.

Bhasin S, Krummen LA, Swerdloff RS, Morelos BS, Kim WH, diZerega GS, Ling N, Esch F, Shimasaki S \& Toppari J 1989 Stage dependent expression of inhibin $\alpha$ and $\beta$-B subunits during the cycle of the rat seminiferous epithelium. Endocrinology 124 987-991.

Buzzard JJ, Farnworth PG, de Kretser DM, O'Connor AE, Wreford NG \& Morrison JR 2003 Proliferative phase Sertoli cells display a developmentally regulated response to activin in vitro. Endocrinology 144 474-483.

Buzzard JJ, Loveland KL, O'Bryan MK, O'Connor AE, Bakker M, Hayashi T, Wreford NG, Morrison JR \& de Kretser DM 2004 Changes in circulating and testicular levels of inhibin A and B and activin A during postnatal development in the rat. Endocrinology 145 3532-3541.

Cho SH, Yao ZB, Wang SW, Alban RF, Barbers RG, French SW \& Oh CK 2003 Regulation of activin A expression in mast cells and asthma: its effect on the proliferation of human airway smooth muscle cells. Journal of Immunology 170 4045-4052.

Clermont Y \& Harvey SC 1965 Duration of the cycle of the seminiferous epithelium of normal, hypophysectomized and hypophysectomizedhormone treated albino rats. Endocrinology 76 80-89.

Clifton RJ, O'Donnell L \& Robertson DM 2002 Pachytene spermatocytes in co-culture inhibit rat Sertoli cell synthesis of inhibin $\beta B$-subunit and inhibin B but not the inhibin $\alpha$-subunit. Journal of Endocrinology 172 565-574.

Cohen PE \& Pollard JW 1998 Normal sexual function in male mice lacking a functional type I interleukin-1 (IL-1) receptor. Endocrinology 139 815-818.

de Winter JP, Vanderstichele HM, Verhoeven G, Timmerman MA, Wesseling JG \& de Jong FH 1994 Peritubular myoid cells from immature rat testes secrete activin-A and express activin receptor type II in vitro. Endocrinology $135759-767$.

Erämaa M, Hurme M, Stenman UH \& Ritvos O 1992 Activin A/erythroid differentiation factor is induced during human monocyte activation. Journal of Experimental Medicine 176 1449-1452.

Gérard N, Syed V, Bardin W, Genetet N \& Jégou B 1991 Sertoli cells are the site of interleukin- $1 \alpha$ synthesis in rat testis. Molecular and Cellular Endocrinology 82 R13-R16.

Gérard N, Syed V \& Jégou B 1992 Lipopolysaccharide, latex beads and residual bodies are potent activators of Sertoli cell interleukin- $1 \alpha$ production. Biochemical and Biophysical Research Communications 185 154-161.

Gonzales GF, Risbridger GP, Hodgson YH, Pöllänen P \& de Kretser DM 1989 Stage-specific inhibin secretion by rat seminiferous tubules. Reproduction, Fertility and Development 1 275-279.

Groome NP, Illingworth PJ, O’Brien M, Pai R, Rodger FE, Mather JP \& McNeilly AS 1996 Measurement of dimeric inhibin B throughout the human menstrual cycle. Journal of Clinical Endocrinology and Metabolism 81 1401-1405.

Hakovirta H, Kaipia A, Söder O \& Parvinen M 1993a Effects of activin-A, inhibin- $A$, and transforming growth factor- $\beta 1$ on stage-specific deoxyribonucleic acid synthesis during rat seminiferous epithelial cycle. Endocrinology 133 1664-1668.

Hakovirta H, Pentitilä TL, Pöllänen P, Fröysa B, Söder O \& Parvinen M $1993 b$ Interleukin-1 bioactivity and DNA synthesis in X-irradiated rat testes. International Journal of Andrology 16 159-164.

Jonsson CK, Zetterström RH, Holst M, Parvinen M \& Söder O 1999 Constitutive expression of interleukin- $1 \alpha$ messenger ribonucleic acid in rat Sertoli cells is dependent upon interaction with germ cells. Endocrinology 140 3755-3761.

Kaipia A, Parvinen M, Shimasaki S, Ling N \& Toppari J 1991 Stage-specific cellular regulation of inhibin $\alpha$-subunit mRNA expression in the rat seminiferous epithelium. Molecular and Cellular Endocrinology 82 165-173. 
Kaipia A, Penttila TL, Shimasaki S, Ling N, Parvinen M \& Toppari J 1992 Expression of inhibin $\beta A$ and $\beta B$, follistatin and activin- $A$ receptor messenger ribonucleic acids in the rat seminiferous epithelium. Endocrinology 131 2703-2710.

Klaij IA, van Pelt AM, Timmerman MA, Blok LJ, de Rooij DG \& de Jong FH 1994 Expression of inhibin subunit mRNAs and inhibin levels in the testes of rats with stage-synchronized spermatogenesis. Journal of Endocrinology 141 131-141.

Knight PG, Muttukrishna S \& Groome NP 1996 Development and application of a two-site enzyme immunoassay for the determination of 'total' activin-A concentrations in serum and follicular fluid. Journal of Endocrinology 148 267-279.

Leblond CP \& Clermont Y 1952 Definition of the stages of the cycle of the seminiferous epithelium in the rat. Annals of the New York Academy of Sciences 55 548-573.

Majdic G, McNeilly AS, Sharpe RM, Evans LR, Groome NP \& Saunders PT 1997 Testicular expression of inhibin and activin subunits and follistatin in the rat and human fetus and neonate and during postnatal development in the rat. Endocrinology 138 2136-2147.

Marchetti C, Hamdane M, Mitchell V, Mayo K, Devisme L, Rigot JM, Beauvillain JC, Hermand E \& Defossez A 2003 Immunolocalization of inhibin and activin $\alpha$ and $\beta_{\mathrm{B}}$ subunits and expression of corresponding messenger RNAs in the human adult testis. Biology of Reproduction $\mathbf{6 8}$ 230-235.

Mather JP, Attie KM, Woodruff TK, Rice GC \& Phillips DM 1990 Activin stimulates spermatogonial proliferation in germ-Sertoli cell cocultures from immature rat testis. Endocrinology 127 3206-3214.

Meehan T, Schlatt S, O’Bryan MK, de Kretser DM \& Loveland KL 2000 Regulation of germ cell and Sertoli cell development by activin, follistatin, and FSH. Developmental Biology 220 225-237.

Meinhardt A, O’Bryan MK, McFarlane JR, Loveland KL, Mallidis C, Foulds LM, Phillips DJ \& de Kretser DM 1998 Localization of follistatin in the rat testis. Journal of Reproduction and Fertility 112 233-241.

Merchenthaler I, Culler MD, Petrusz P \& Negro-Vilar A 1987 Immunocytochemical localization of inhibin in rat and human reproductive tissues. Molecular and Cellular Endocrinology 54 239-243.

O’Bryan MK, Schlatt S, Phillips DJ, de Kretser DM \& Hedger MP 2000 Bacterial lipopolysaccharide-induced inflammation compromises testicular function at multiple levels in vivo. Endocrinology 141 238-246.

O'Bryan MK, Gerdprasert O, Nikolic-Paterson DP, Meinhardt A, Muir JA, Foulds LK, Phillips DJ, de Kretser DM \& Hedger MP 2005 Cytokine profiles in the testes of rats treated with lipopolysaccharide reveal localized suppression of inflammatory responses. American Journal of Physiology: Regulatory, Integrative and Comparative Physiology 288 R1744-R1755.

Okuma Y, Saito K, O'Connor AE, Phillips DJ, de Kretser DM \& Hedger MP $2005 a$ Reciprocal regulation of activin A and inhibin B by interleukin-1 (IL-1) and follicle-stimulating hormone (FSH) in rat Sertoli cells in vitro. Journal of Endocrinology 185 99-110.

Okuma Y, O'Connor AE, Muir JA, Stanton PG, de Kretser DM \& Hedger MP $2005 b$ Regulation of activin A and inhibin B secretion by inflammatory mediators in adult rat Sertoli cell culture. Journal of Endocrinology 187 $125-134$.
Parvinen M \& Ruokonen A 1982 Endogenous steroids in the rat seminiferous tubules comparison of the stages of the epithelial cycle isolated by trans illumination assisted micro dissection. Journal of Andrology 3 211-220.

Parvinen M, Söder O, Mali P, Fröysa B \& Ritzén EM 1991 In vitro stimulation of stage-specific deoxyribonucleic acid synthesis in rat seminiferous tubule segments by interleukin-1 $\alpha$. Endocrinology 129 1614-1620.

Phillips DJ, Jones KL, Scheerlinck JY, Hedger MP \& de Kretser DM 2001 Evidence for activin A and follistatin involvement in the systemic inflammatory response. Molecular and Cellular Endocrinology 180 155-162.

Pineau C, Sharpe RM, Saunders PT, Gérard N \& Jégou B 1990 Regulation of Sertoli cell inhibin production and of inhibin $\alpha$-subunit mRNA levels by specific germ cell types. Molecular and Cellular Endocrinology 72 13-22.

Pöllänen P, Söder O \& Parvinen M 1989 Interleukin- $1 \alpha$ stimulation of spermatogonial proliferation in vivo. Reproduction, Fertility and Development 1 $85-87$.

Roberts V, Meunier H, Sawchenko PE \& Vale W 1989 Differential production and regulation of inhibin subunits in rat testicular cell types. Endocrinology 125 2350-2359.

Robertson DM, Foulds LM, Prisk M \& Hedger MP 1992 Inhibin/activin $\beta$-subunit monomer: isolation and characterization. Endocrinology $\mathbf{1 3 0}$ 1680-1687.

Shaha C, Morris PL, Chen CL, Vale W \& Bardin CW 1989 Immunostainable inhibin subunits are in multiple types of testicular cells. Endocrinology $\mathbf{1 2 5}$ 1941-1950.

Söder O, Syed V, Callard GV, Toppari J, Pöllänen P, Parvinen M, Fröysa B \& Ritzén EM 1991 Production and secretion of an interleukin-1-like factor is stage-dependent and correlates with spermatogonial DNA synthesis in the rat seminiferous epithelium. International Journal of Andrology 14 223-231.

Syed V, Stéphan JP, Gérard N, Legrand A, Parvinen M, Bardin CW \& Jégou B 1995 Residual bodies activate Sertoli cell interleukin- $1 \alpha$ (IL-1 $\alpha)$ release, which triggers IL-6 production by an autocrine mechanism, through the lipoxygenase pathway. Endocrinology 136 3070-3078.

Tanimoto K, Yoshida E, Mita S, Nibu Y, Murakami K \& Fukamizu A 1996 Human activin $\beta$ A gene, Identification of novel $5^{\prime}$ exon, functional promoter, and enhancers. Journal of Biological Chemistry 271 32760-32769.

Wang JE, Josefsen GM, Hansson V \& Haugen TB 1998 Residual bodies and IL- $1 \alpha$ stimulate expression of mRNA for IL- $1 \alpha$ and IL- 1 receptor type I in cultured rat Sertoli cells. Molecular and Cellular Endocrinology 137 139-144.

Yoshida E, Tanimoto K, Murakami K \& Fukamizu A 1998 Isolation and characterization of $5^{\prime}$-regulatory region of mouse activin $\beta$ A subunit gene. Biochemistry and Molecular Biology International 44 325-332.

Zeyse D, Lunenfeld E, Beck M, Prinsloo I \& Huleihel M 2000 Interleukin-1 receptor antagonist is produced by Sertoli cells in vitro. Endocrinology 141 $1521-1527$.

Received 19 December 2005

Received in final form 4 May 2006

Accepted 8 May 2006

Made available online as an Accepted Preprint

11 May 2006 